\title{
Guest-host interaction of $\mathrm{K}_{0.34} \mathrm{Co}\left[\mathrm{Fe}(\mathrm{CN})_{6}\right]_{0.75} \cdot{ } \mathrm{H}_{2} \mathrm{O}$ as investigated by a charge-density analysis
}

\author{
J. E. Kim, ${ }^{1}$ K. Kato, ${ }^{2}$ M. Takata, ${ }^{2}$ T. Shibata, ${ }^{3}$ and Y. Moritomo ${ }^{3}$ \\ ${ }^{1}$ JASRI/SPring-8, 1-1-1 Kouto, Sayo-cho, Sayo-gun, Hyogo 679-5198, Japan \\ ${ }^{2}$ RIKEN SPring-8 Center, 1-1-1 Kouto, Sayo-cho, Sayo-gun, Hyogo 679-5148, Japan \\ ${ }^{3}$ Department of Physics, University of Tsukuba, Tsukuba 305-8571, Japan
}

(Received 25 December 2008; published 16 April 2009)

\begin{abstract}
Charge-density level structure was determined in a prototypical nanoporous material with strong guest-host interaction, $\mathrm{K}_{0.34} \mathrm{Co}\left[\mathrm{Fe}(\mathrm{CN})_{6}\right]_{0.75} \cdot z \mathrm{H}_{2} \mathrm{O}(z=3.6$ and 2.7). We determined atomic coordinates and occupancies $(\mathrm{g})$ of three kinds of oxygen sites of guest waters, i.e., zeolite water, ligand water, and off-axis water, as a function of $z$. The variation in $g$ against $z$ indicates easily removable nature of the zeolite and off-axis waters, and robust coordination bond with the ligand water. Significant change in the charge density of the host-NCFe-CN-Co-NC-Fe-CN-lattice revealed hybridization effect between the off-axis water and the adjacent Co atom.
\end{abstract}

DOI: 10.1103/PhysRevB.79.132105

PACS number(s): 61.05.cp

Recently, nanoporous material is attracting interest of materials scientists because the nanospaces of the host lattice can be utilized as storage of the guest molecules, such as $\mathrm{O}_{2}$, $\mathrm{H}_{2} \mathrm{O}$, NO, and so on. ${ }^{1}$ In an extreme case, the lowdimensional alignment of the nanospaces induces an interesting physical property of the guest molecules. ${ }^{2}$ Another feature of the nanoporous material is that guest-host interaction can modify physical properties of the host lattice. Prussian blue analog $A_{x} M\left[\mathrm{Fe}(\mathrm{CN})_{6}\right]_{y} \cdot z \mathrm{H}_{2} \mathrm{O}$ ( $A$ is alkaline metal and $M$ is transition metal) is a prototypical nanoporous material with strong interaction between guest waters and host lattice. In this compound, removal of the guest waters by humidity, ${ }^{3}$ heat treatment, ${ }^{4}$ and reduced pressure ${ }^{5,6}$ significantly alters the physical properties of the host lattice. Ohkoshi et $a .^{3}$ reported that magnetic properties of $\left(\mathrm{Co}_{x}^{\mathrm{II}} \mathrm{Mn}_{1-x}^{\mathrm{II}}\right)\left[\mathrm{Cr}{ }^{\mathrm{III}}(\mathrm{CN})_{6}\right]_{2 / 3} \cdot z \mathrm{H}_{2} \mathrm{O}$ can be controlled by humidity, and ascribed the phenomena to formation of tetrahedral coordination of $\mathrm{Co}^{\mathrm{II}}$ ions. On the other hand, MartinezGarcia et $a l .{ }^{4}$ reported variation in the magnetic properties of $M^{\mathrm{II}}\left[\mathrm{Fe}^{\mathrm{III}}(\mathrm{CN})_{6}\right]_{2 / 3} \cdot z \mathrm{H}_{2} \mathrm{O}(M=\mathrm{Mn}, \mathrm{Co}, \mathrm{Ni}, \mathrm{Cu})$ by desorption, and ascribed the effects to compression of the $M$-Fe bond distance. Moritomo et al. ${ }^{5}$ reported a huge desorption effect on the charge-transfer (CT) transition from $\mathrm{Co}^{\mathrm{II}}-\mathrm{Fe}^{\mathrm{III}}$ [hightemperature (HT) phase] to $\mathrm{Co}^{\mathrm{III}}-\mathrm{Fe}^{\mathrm{II}}[$ low-temperature (LT) phase $]$ in a film of $\mathrm{Na}_{0.20} \mathrm{Co}\left[\mathrm{Fe}(\mathrm{CN})_{6}\right]_{0.71} \cdot z \mathrm{H}_{2} \mathrm{O}$. The critical temperature $T_{\mathrm{CT}}$ for the $\mathrm{CT}$ transition increases as $T_{\mathrm{CT}}$ $=298-28 z(z \geq 1.5)$ with decrease in $z$ but the transition suddenly disappears below $z=1.5$ and the system remains in the HT phase down to $10 \mathrm{~K}$. In addition, desorption of the guest waters significantly alters electronic state of the $\mathrm{Co}^{\mathrm{II}}$ ions below $z=1.5$, as evidenced by significant broadening of $\mathrm{x}$-ray absorption near-edge structure (XANES) around the Co $K$ edge. ${ }^{7}$ The controllability of the magnetic, electronic, and structural properties by guest water concentration $(z)$ proves potential ability of the Prussian blue lattice.

Crystallographically, Prussian blue analog belongs to a face-centered-cubic lattice ${ }^{8,9}$ with three-dimensional cyanobridged-NC-Fe-CN-Co-NC-Fe-CN-network, which can be regarded as host lattice (Prussian blue lattice). A part of guest waters (zeolite water) is accommodated within the network while another part of guest waters (ligand water) replaces the
$\left[\mathrm{Fe}(\mathrm{CN})_{6}\right]$ unit to coordinate the Co ions. Herren et al. ${ }^{9}$ determined the oxygen positions, i.e., zeolite site ( $8 c$ and $32 f)$ and the ligand site $(24 c)$ in $F m \overline{3} m$ model, for $\mathrm{Fe}^{\mathrm{III}}\left[\mathrm{Fe}^{\mathrm{II}}(\mathrm{CN})_{6}\right]_{3 / 4} \cdot 3.5 \mathrm{H}_{2} \mathrm{O}$ by means of the neutron powder structural analysis. Matsuda et al., ${ }^{10}$ however, proposed off-axis site (96i) instead of ligand site for $\mathrm{Mn}^{\mathrm{II}}\left[\mathrm{Fe}^{\mathrm{III}}(\mathrm{CN})_{6}\right]_{2 / 3} \cdot 5 \mathrm{H}_{2} \mathrm{O}$ by means of the single-crystal $\mathrm{X}$-ray structural analysis. Thus, even the position of the guest waters within the host lattice is still controversial. To explore the rich desorption effects in the Prussian blue analogs and to comprehend the origin of the effects, we need to clarify interaction between the guest waters at respective crystallographic sites and the Prussian blue lattice.

In this paper, we investigated charge-density level structure of $z$-controlled $\mathrm{K}_{0.34} \mathrm{Co}\left[\mathrm{Fe}(\mathrm{CN})_{6}\right]_{0.75} \cdot z \mathrm{H}_{2} \mathrm{O}$ by means of maximum entropy method (MEM) combined with the $\mathrm{Ri}$ etveld refinement (MEM/Rietveld method). ${ }^{11-13}$ Atomic coordinates and occupancies $(g)$ of three kinds of oxygen sites of the guest waters, i.e., zeolite water, ligand water, and offaxis water, are determined as a function of $z$. These water positions suggest formation of hydrogen bonding between the zeolite and the off-axis waters, which perhaps is the reason for the existence of the low-symmetry off-axis site. Significant change in the charge density of the host lattice revealed hybridization effect between the off-axis water and the adjacent $\mathrm{Co}$ atom.

Powders of $\mathrm{K}_{0.34} \mathrm{Co}\left[\mathrm{Fe}(\mathrm{CN})_{6}\right]_{0.75} \cdot 3.6 \mathrm{H}_{2} \mathrm{O}$ were prepared by reacting an aqueous solution of $\mathrm{FeCl}_{2}, \mathrm{KCl}$, and $\mathrm{K}_{3}\left[\mathrm{Fe}(\mathrm{CN})_{6}\right]$. Chemical compositions of the prepared samples were determined by inductively coupled plasma (ICP) and standard microanalytical methods. Thermogravimetric curve of the powders shows a sudden drop at $\approx 100{ }^{\circ} \mathrm{C}$, and then becomes constant up to $\approx 220{ }^{\circ} \mathrm{C}$. Water content $z$ was controlled by a heat treatment $\left(180{ }^{\circ} \mathrm{C}\right.$ for 15 min) and was determined at $z=2.7$ by standard microanalytical method. We compared the $\mathrm{x}$-ray diffraction patterns before and after the heat treatment, and found no deterioration of the peak profiles. Temperature variation in magnetic susceptibility $\chi$ was measured with a superconducting quantum interference device magnetometer under a field of $1000 \mathrm{G}$. An anomaly due to the CT transition is observed in the $\chi-T$ 
(a)

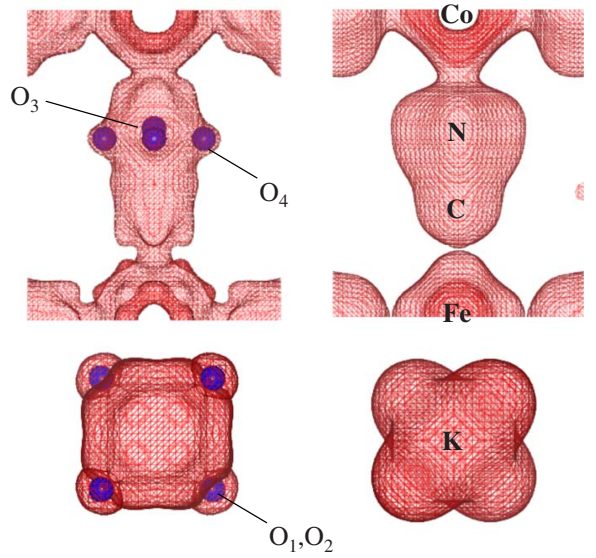

FIG. 1. (Color online) (a) Isosurface of MEM charge density at $0.6 e / \AA^{3}$ of $\mathrm{K}_{0.34} \mathrm{Co}\left[\mathrm{Fe}(\mathrm{CN})_{6}\right]_{0.75} \cdot 3.6 \mathrm{H}_{2} \mathrm{O}$ around the Co-NC-Fe bond and $\mathrm{K}$ atom. The charge density was estimated based on a series of structure factors $F_{h k l}$ determined based on the structural mode without oxygen. Spheres represent extra charge density due to oxygen. (b) Isosurface at $0.6 \mathrm{e} / \AA^{3}$ of $\mathrm{K}_{0.34} \mathrm{Co}\left[\mathrm{Fe}(\mathrm{CN})_{6}\right]_{0.75} \cdot 3.6 \mathrm{H}_{2} \mathrm{O}$ around the $\mathrm{Co}-\mathrm{NC}-\mathrm{Fe}$ bond and $\mathrm{K}$ atom. The charge density was estimated based on the $F_{h k l}$ series determined based on the structural model with the oxygen.

curve at $T_{\mathrm{CT}}=260 \mathrm{~K}$ in the $z=3.6$ sample while $T_{\mathrm{CT}}$ exceeds $300 \mathrm{~K}$ in the $x=2.6$ sample. To obtain $\mathrm{x}$-ray powderdiffraction pattern of high statistics with high angular resolution, measurements were carried out at SPring-8 BL02B2 beamline. ${ }^{14}$ The sample powders were sealed in a $0.3 \mathrm{~mm} \phi$ capillary whose temperature was maintained at $90 \mathrm{~K}$ with cooled nitrogen gas. The wavelength of the $\mathrm{x}$ ray (=0.502 $52 \AA)$ was calibrated by the lattice constant of standard $\mathrm{CeO}_{2}$ powders. The diffraction patterns were collected on an imaging plate installed on a large Debye-Scherrer camera $(r=286.5 \mathrm{~mm})$.

One of the significant feature of the MEM/Rietveld method is the predictability of the unknown atomic position. ${ }^{15}$ In this method, a series of complex structure fac- tors $F_{h k l}$ is estimated from the diffraction pattern based on the Rietveld refinement, which decomposes the overlapped reflection and determines the phase of $F_{h k l}$. Then, the most probable charge density is estimated by the MEM analysis from the $F_{h k l}$ series. In some cases, the MEM charge density tells us a more probable structural model ("predictability"). We show in Fig. 1(a) isosurface of MEM charge density at $0.6 e / \AA^{3}$ of $\mathrm{K}_{0.34} \mathrm{Co}\left[\mathrm{Fe}(\mathrm{CN})_{6}\right]_{0.75} \cdot 3.6 \mathrm{H}_{2} \mathrm{O} \quad(z=3.6)$ around the Co-NC-Fe bond and $\mathrm{K}$ atom. The charge density was estimated from the $F_{h k l}$ series, determined based on the structural model without oxygen $(F \overline{4} 3 m ; Z=4)$. Extra charge density is observed at the $16 e\left(\mathrm{O}_{1}\right.$ and $\left.\mathrm{O}_{2}\right), 24 f\left(\mathrm{O}_{3}\right)$, and $96 i$ $\left(\mathrm{O}_{4}\right)$ sites, and is ascribed to oxygen atom [see spheres in Fig. 1(a)]. The $\mathrm{O}_{1}$ and $\mathrm{O}_{2}$ (zeolite) sites locate at the nanopore while $\mathrm{O}_{3}$ (ligand) and $\mathrm{O}_{4}$ (off-axis) sites locate in the void due to the $\left[\mathrm{Fe}(\mathrm{CN})_{6}\right]$ vacancy. Thus, we can modify the structural model by including the oxygen sites. We listed in Tables I and II the final structural parameters for $\mathrm{K}_{0.34} \mathrm{Co}\left[\mathrm{Fe}(\mathrm{CN})_{6}\right]_{0.75} \cdot 3.6 \mathrm{H}_{2} \mathrm{O} \quad(z=3.6) \quad$ and $\mathrm{K}_{0.34} \mathrm{Co}\left[\mathrm{Fe}(\mathrm{CN})_{6}\right]_{0.75} \cdot 2.7 \mathrm{H}_{2} \mathrm{O} \quad(z=2.7)$, respectively. The MEM charge-density analysis was carried out with a program ENIGMA (Ref. 16) using $128 \times 128 \times 128$ pixels. The $R_{I}$ factors based on the MEM charge densities are $2.7 \%$ $(2.2 \%)$ at $z=3.6(z=2.7)$. The number of the $F_{h k l}$ were 248 (248) at $z=3.6(z=2.7)$. The final charge density is exemplified in Fig. 1(b) at $z=3.6$. Our structural analysis indicates that the off-axis water coexists with the ligand water, making a sharp contrast with the result reported by Matsuda et al. ${ }^{10}$ Consistently with our analysis, Takeda et al. ${ }^{17}$ performed a magic angle spinning (MAS) deutron NMR [ ${ }^{2} \mathrm{D}-\mathrm{MAS}$ NMR (Ref. 18)] for $\mathrm{Na}_{0.40} \mathrm{Co}\left[\mathrm{Na}(\mathrm{CN})_{6}\right]_{0.79} \cdot z \mathrm{D}_{2} \mathrm{O}$ and found three signals, whose isotropic shifts are $2 \mathrm{ppm}(49 \%),-13 \mathrm{ppm}$ $(20 \%)$, and $-39 \mathrm{ppm}(31 \%)$ at $364 \mathrm{~K}$. The water site at 2 ppm, which negligibly interacts with magnetic ions, should be ascribed to the zeolite water $(41 \%)$ while the isotropic shift of $-39 \mathrm{ppm}$ is ascribed to the coordination bond of the ligand water $(25 \%)$. Then, the remaining site at $-13 \%$ can be ascribed to the off-axis water (34\%). These assignments suggest coordination bond between the off-axis water and the neighboring Co (vide infra).

TABLE I. Occupancy $g$, atomic positions $(x, y, z)$, and isotropic atomic displacement parameter $B$ of $\mathrm{K}_{0.34} \mathrm{Co}\left[\mathrm{Fe}(\mathrm{CN})_{6}\right]_{0.75} \cdot 3.6 \mathrm{H}_{2} \mathrm{O}(z=3.6)$ at $90 \mathrm{~K}$. The crystal symmetry is face-centered cubic $(F \overline{4} 3 m ; Z=4)$ with $a=9.93440(4) \AA . R_{\mathrm{wp}}\left(\equiv\left[\frac{\Sigma_{i} w_{i}\left(y_{i}-y_{i, \text { calc }}\right)^{2}}{\Sigma_{i} w_{i} y_{i}^{2}}\right]^{1 / 2}\right)$ and $R_{I}\left(\equiv \frac{\Sigma_{K}\left|I_{K, \text { calc }}-I_{K}\right|}{\Sigma_{K} I_{K, \text { calc }}}\right)$ are $2.69 \%$ and $3.29 \%$, respectively.

\begin{tabular}{|c|c|c|c|c|c|c|}
\hline Atom & Site & $g$ & $x$ & $y$ & $z$ & $\begin{array}{c}B \\
\left(\AA^{2}\right)\end{array}$ \\
\hline $\mathrm{Fe}$ & $4 a$ & 0.75 & 0 & 0 & 0 & $1.37(2)$ \\
\hline Co & $4 b$ & 1 & $1 / 2$ & 0 & 0 & $1.31(1)$ \\
\hline $\mathrm{K}_{1}$ & $4 c$ & $0.16957(125)$ & $1 / 4$ & $1 / 4$ & $1 / 4$ & $2.6(2)$ \\
\hline $\mathrm{K}_{2}$ & $4 d$ & $0.17043(125)$ & $3 / 4$ & $3 / 4$ & $3 / 4$ & $2.6(2)$ \\
\hline $\mathrm{C}$ & $24 f$ & 0.75 & $0.18023(12)$ & 0 & 0 & $1.51(5)$ \\
\hline $\mathrm{N}$ & $24 f$ & 0.75 & $0.29599(5)$ & 0 & 0 & $1.81(3)$ \\
\hline $\mathrm{O}_{1}$ & $16 e$ & $0.18980(125)$ & $0.21396(106)$ & $0.21396(106)$ & $0.21396(106)$ & $2.4(2)$ \\
\hline $\mathrm{O}_{2}$ & $16 e$ & $0.17958(495)$ & $0.80115(209)$ & $0.80115(209)$ & $0.80115(209)$ & $2.4(2)$ \\
\hline $\mathrm{O}_{3}$ & $24 f$ & $0.14702(208)$ & $0.30752(85)$ & 0 & 0 & $2.4(2)$ \\
\hline $\mathrm{O}_{4}$ & $96 i$ & $0.05151(88)$ & $0.08185(80)$ & $0.31987(113)$ & 0 & $5.7(5)$ \\
\hline
\end{tabular}


TABLE II. Occupancy $g$, atomic positions $(x, y, z)$, and isotropic atomic displacement parameter $B$ of $\mathrm{K}_{0.34} \mathrm{Co}\left[\mathrm{Fe}(\mathrm{CN})_{6}\right]_{0.75} \cdot 2.7 \mathrm{H}_{2} \mathrm{O}(z=2.7)$ at $90 \mathrm{~K}$. The crystal symmetry is face-centered cubic $(F \overline{4} 3 \mathrm{~m}$; $Z=4)$ with $a=9.96589(3) \AA . R_{\mathrm{wp}}$ and $R_{I}$ are $2.29 \%$ and $3.84 \%$, respectively.

\begin{tabular}{lllcccl}
\hline \hline Atom & Site & \multicolumn{1}{c}{$g$} & \multicolumn{1}{c}{$y$} & \multicolumn{1}{c}{$\begin{array}{c}B \\
\left(\AA^{2}\right)\end{array}$} \\
\hline $\mathrm{Fe}$ & $4 a$ & 0.75 & 0 & 0 & 0 & $1.56(1)$ \\
$\mathrm{Co}$ & $4 b$ & 1 & $1 / 2$ & 0 & 0 & $1.70(1)$ \\
$\mathrm{K}_{1}$ & $4 c$ & $0.16984(142)$ & $1 / 4$ & $1 / 4$ & $1 / 4$ & $3.0(1)$ \\
$\mathrm{K}_{2}$ & $4 d$ & $0.17016(142)$ & $3 / 4$ & $3 / 4$ & $3 / 4$ & $3.0(1)$ \\
$\mathrm{C}$ & $24 f$ & 0.75 & $0.18005(10)$ & 0 & 0 & $2.75(5)$ \\
$\mathrm{N}$ & $24 f$ & 0.75 & $0.29536(4)$ & 0 & 0 & $2.69(3)$ \\
$\mathrm{O}_{1}$ & $16 e$ & $0.11010(142)$ & $0.20108(162)$ & $0.20108(162)$ & $0.20108(162)$ & $3.0(5)$ \\
$\mathrm{O}_{2}$ & $16 e$ & $0.09540(1007)$ & $0.79587(466)$ & $0.79587(466)$ & $0.79587(466)$ & $3.0(5)$ \\
$\mathrm{O}_{3}$ & $24 f$ & $0.14684(137)$ & $0.30875(90)$ & 0 & 0 & $3.2(6)$ \\
$\mathrm{O}_{4}$ & $96 i$ & $0.04130(115)$ & $0.06600(78)$ & $0.31462(194)$ & 0 & $4.2(6)$ \\
\hline \hline
\end{tabular}

We listed in Table III compositions of the respective water sites of $\mathrm{K}_{0.34} \mathrm{Co}\left[\mathrm{Fe}(\mathrm{CN})_{6}\right]_{0.75} \cdot z \mathrm{H}_{2} \mathrm{O}$ as a function of $z$. The water compositions at $z=3.6$ are quite reasonable if we assume that the lost $\mathrm{CN}$ groups (1.5 per Co site) are replaced by the single ligand water $\left(\mathrm{O}_{3} ; 0.88\right.$ per $\mathrm{Co}$ site $)$ or the pair of the off-axis waters $\left(\mathrm{O}_{4} ; 0.62\right.$ per Co site $)$. We found that $\mathrm{O}_{1}-\mathrm{O}_{4}\left(\mathrm{O}_{2}-\mathrm{O}_{4}\right)$ bond distance is 2.71(1) $\AA$ [2.58(1) $\left.\AA\right]$, and is comparable with the $\mathrm{O}-\mathrm{O}$ bond distance $(2.4-2.7 \AA$ ) connected by the hydrogen bond. We, therefore, think that formation of the hydrogen bonding between the zeolite and the off-axis waters is the reason for the existence of the lowsymmetry off-axis site. A similar argument is performed by Matsuda et al. ${ }^{10}$ It is interesting that a distorted dodecahedron $\left(3 \mathrm{O}_{1}+3 \mathrm{O}_{2}+12 \mathrm{O}_{4}\right)$ appears within the void if we link the $\mathrm{O}_{1}-\mathrm{O}_{4}$ and $\mathrm{O}_{2}-\mathrm{O}_{4}$ hydrogen bonds. Such a dodecahedron would be configured with the aid of the interaction between $\mathrm{O}_{4}$ and the neighboring Co atom (vide infra), and should not be regarded as an isolated cluster. The zeolite water locates around the central position of the nanopore and has negligible interaction with the host lattice, which causes the easily removable nature of the zeolite water (reduction is $44.9 \%$ ). On the other hand, the ligand water has a robust coordination bond with the adjacent Co atom of the host lattice, and hence is hardly removable (reduction is $0.1 \%$ ). The off-axis water shows an intermediate behavior (reduction is 19.8\%), suggesting an electronic interaction with the neighboring Co atom of the host lattice. Such a site-dependent desorption well explains the huge desorption effect on the CT transition observed in the Co-Fe compound. ${ }^{5}$ In the large- $z$ region, only

TABLE III. Compositions of respective water sites for $\mathrm{K}_{0.34} \mathrm{Co}\left[\mathrm{Fe}(\mathrm{CN})_{6}\right]_{0.75} \cdot z \mathrm{H}_{2} \mathrm{O}$.

\begin{tabular}{lcccc}
\hline \hline & Site & $z=3.6$ & $z=2.7$ & Reduction \\
\hline Zeolite site & $\mathrm{O}_{1}$ and $\mathrm{O}_{2}$ & 1.492 & 0.822 & $44.9 \%$ \\
Ligand site & $\mathrm{O}_{3}$ & 0.882 & 0.881 & $0.1 \%$ \\
Off-axis site & $\mathrm{O}_{4}$ & 1.236 & 0.991 & $19.8 \%$ \\
Total & $\mathrm{O}_{4}$ & 3.610 & 2.694 & $34.9 \%$ \\
\hline \hline
\end{tabular}

the zeolite waters are removed. Resultant reduction in the cell volume stabilizes the LT phase, whose cell volume is $\sim 10 \%$ smaller than that of the HT phase. In the small- $z$ region, however, the ligand and off-axis waters begin to be removed. The removal of these waters significantly alters the electronic configuration of the Co site, and can completely suppress the phase transition as observed.

Figure 2 shows MEM charge density of $\mathrm{K}_{0.34} \mathrm{Co}\left[\mathrm{Fe}(\mathrm{CN})_{6}\right]_{0.75} \cdot z \mathrm{H}_{2} \mathrm{O}$ for the (100) section containing $\mathrm{Mn}, \mathrm{Fe}, \mathrm{C}$, and $\mathrm{N}$ atoms at $90 \mathrm{~K}$. The MEM charge density clearly exhibits charge density of the $\mathrm{Co}-\mathrm{N}$ and the $\mathrm{Fe}-\mathrm{C}$ bonds. The off-axis $\left(\mathrm{O}_{4}\right)$ site is discernible as transversal

$$
\mathrm{K}_{0.34} \mathrm{Co}\left[\mathrm{Fe}(\mathrm{CN})_{6}\right]_{0.75} \mathrm{zH}_{2} \mathrm{O}
$$

(a) $z=3.6$

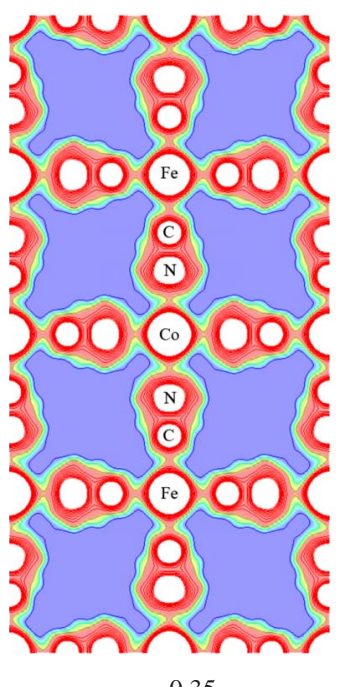

0.35 (b) $z=2.7$

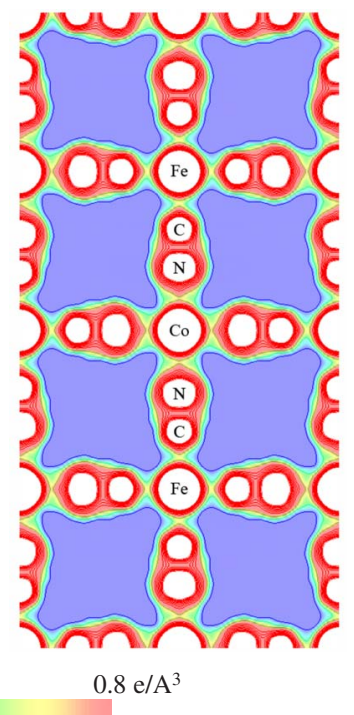

FIG. 2. (Color online) (a) MEM charge density of $\mathrm{K}_{0.34} \mathrm{Co}\left[\mathrm{Fe}(\mathrm{CN})_{6}\right]_{0.75} \cdot 3.6 \mathrm{H}_{2} \mathrm{O}(z=3.6)$ for the (100) section containing $\mathrm{Fe}, \mathrm{Co}, \mathrm{C}$, and $\mathrm{N}$ atoms at $90 \mathrm{~K}$. (b) Charge density of $\mathrm{K}_{0.34} \mathrm{Co}\left[\mathrm{Fe}(\mathrm{CN})_{6}\right]_{0.75} \cdot 2.7 \mathrm{H}_{2} \mathrm{O} \quad(z=2.7)$ for the $(100)$ section at 90 $\mathrm{K}$. Contour lines are drawn from 0.35 to $3.0 e \AA^{-3}$ at intervals of $0.5 e \AA^{-3}$. 
expanse of the charge density at the $\mathrm{N}$ site [see the central part of Fig. 2(a)]. One may notice that the charge density of the $\mathrm{Fe}-\mathrm{C}$ bond is significantly suppressed as $z$ decreases: minimum of the charge density of the Co-N bond is $0.80 e \AA^{-3}\left(0.68 e \AA^{-3}\right)$ at $z=3.6(z=2.7)$. In the Prussian blue analog, the charge density of the bonding electron decreases with increase in the bond distance, as exemplified by the $\mathrm{Mn}-\mathrm{N}$ bond of $\mathrm{RbMn}\left[\mathrm{Fe}(\mathrm{CN})_{6}\right] .{ }^{12}$ The $\mathrm{Fe}-\mathrm{C}$ bond distance $d_{\mathrm{Fe}-\mathrm{C}}$, however, slightly increases with decrease in $z: d_{\mathrm{Fe}-\mathrm{C}}=1.79048(1) \AA$ at $z=3.6$ and $d_{\mathrm{Fe}-\mathrm{C}}=1.79436(1) \AA$ at $z=2.7$. Therefore, the variation in the charge density of the $\mathrm{Fe}-\mathrm{C}$ bond cannot be ascribed to structural modification induced by removal of the zeolite waters. We rather think that the variation in the charge density is due to the hybridization effect between $\mathrm{O}_{4}$ and the host lattice. This idea is further supported by the fact that the charge density of the Co-N bond is also slightly suppressed with $z$ : minimum of the charge density of the Co-N bond is $0.76 e \AA^{-3}\left(0.74 e \AA^{-3}\right)$ at $z=3.6(z=2.7)$. The suppressed charge density can be ascribed to the bonding electron between the removed $\mathrm{O}_{4}$ at- oms and the host lattice. Thus, our charge-density level structural analysis revealed the electronic aspect of the guest-host interaction in the Prussian blue analog.

In summary, we investigated the charge-density level structure of $z$-controlled $\mathrm{K}_{0.34} \mathrm{Co}\left[\mathrm{Fe}(\mathrm{CN})_{6}\right]_{0.75} \cdot z \mathrm{H}_{2} \mathrm{O}$. We nonempirically determined three kinds of oxygen sites of the guest waters, i.e., zeolite, ligand, and off-axis waters. Among them, the off-axis water has intermediate nature between the zeolite and the ligand waters, and is barely removable due to the strong guest-host interaction. The microscopic information on the guest waters will contribute to deeper comprehension as well as effective exploration of the rich desorption effect in the Prussian blue analogs.

This work was supported by a Grant-In-Aid for Scientific Research from the Ministry of Education, Culture, Sports, and Science. The synchrotron-radiation $\mathrm{x}$-ray powderdiffraction experiments were performed at the SPring- 8 BL02B2 beamline with approval of the Japan Synchrotron Radiation Research Institute (JASRI).
${ }^{1}$ S. Kitagawa, R. Kitaura, and S. Noro, Angew. Chem., Int. Ed. 43, 2334 (2004).

${ }^{2}$ R. Kitaura et al., Science 298, 2358 (2002).

${ }^{3}$ S. Ohkoshi, K. Arai, Y. Sato, and K. Hashimoto, Nature Mater. 3, 857 (2004).

${ }^{4}$ R. Martinez-Garcia, M. Knobel, and E. Reguera, J. Phys.: Condens. Matter 18, 11243 (2006).

${ }^{5}$ Y. Moritomo, F. Nakada, J. E. Kim, and M. Takata, Appl. Phys. Express 1, 111301 (2008).

${ }^{6}$ Y. Moritomo, F. Nakada, H. Kamioka, J. E. Kim, and M. Takata, Appl. Phys. Lett. 92, 141907 (2008).

${ }^{7}$ Y. Moritomo et al. (unpublished).

${ }^{8}$ A. Ludi and H. U. Güdel, Struct. Bonding (Berlin) 14, 1 (1973).

${ }^{9}$ F. Herren, P. Fischer, A. Ludi, and W. Haelg, Inorg. Chem. 19, 956 (1980).

${ }^{10}$ T. Matsuda, H. Tokoro, M. Shiro, K. Hashimoto, and S. Ohokoshi, Acta Crystallogr., Sect. E: Struct. Rep. Online 64, i11
(2008).

${ }^{11}$ M. Takata, Acta Crystallogr., Sect. A: Found. Crystallogr. 64, 232 (2008).

${ }^{12}$ K. Kato, Y. Moritomo, M. Takata, M. Sakata, M. Umekawa, N. Hamada, S. Ohkoshi, H. Tokoro, and K. Hashimoto, Phys. Rev. Lett. 91, 255502 (2003).

${ }^{13}$ K. Kato, M. Takata, Y. Moritomo, A. Nakamoto, and N. Kojima, Appl. Phys. Lett. 90, 201902 (2007).

${ }^{14}$ E. Nishibori et al., Nucl. Instrum. Methods Phys. Res. A 467468, 1045 (2001).

${ }^{15}$ For example, see Y. Kubota et al., Angew. Chem., Int. Ed. 44, 920 (2005).

${ }^{16}$ H. Tanaka et al., J. Appl. Crystallogr. 35, 282 (2002).

${ }^{17}$ S. Takeda, Y. Umehara, H. Hara, and G. Murata, Mol. Cryst. Liq. Cryst. 379, 253 (2002).

${ }^{18}$ G. Murata et al., J. Am. Chem. Soc. 121, 424 (1999). 